TITLE:

\title{
Visible-light photoexcitation of pyridine surface complex, leading to selective dehydrogenative cross- coupling with cyclohexane
}

\section{$\operatorname{AUTHOR}(S)$ :}

Naniwa, Shimpei; Tyagi, Akanksha; Yamamoto, Akira; Yoshida, Hisao

\section{CITATION:}

Naniwa, Shimpei ...[et al]. Visible-light photoexcitation of pyridine surface complex, leading to selective dehydrogenative cross-coupling with cyclohexane. Physical Chemistry Chemical Physics 2018, 20(45): 28375-28381

\section{ISSUE DATE:}

2018-12-07

URL:

http://hdl.handle.net/2433/235622

\section{RIGHT:}

This is the accepted manuscript of the article, which has been published in final form at

https://doi.org/10.1039/C8CP04292F.; The full-text file will be made open to the public on 18 August 2019 in accordance with publisher's 'Terms and Conditions for Self-Archiving'.; This is not the published version. Please cite only the published version.; この論文は出版社版でありません。引用の際には出版社版をご確認ご利用ください。 


\section{Journal Name}

\section{ARTICLE}

\section{Visible light photoexcitation of pyridine surface complex leading to selective dehydrogenative cross-coupling with cyclohexanet}

Received 00th January 20xx Accepted 00th January 20xx

DOI: $10.1039 / \times 0 \times x 00000 x$

www.rsc.org/

\begin{abstract}
Shimpei Naniwa, ${ }^{a}$ Akanksha Tyagi, ${ }^{a}$ Akira Yamamoto ${ }^{a, b}$ and Hisao Yoshida*a,b
Upon photoirradiation with visible light, a pyridine molecule adsorbed on $\mathrm{TiO}_{2}$ surface can be photoexcited to give a pyridine radical cation via ligand to metal charge transfer (LMCT) between pyridine and titanium. This leads to dehydrogenative crosscoupling (DCC) between pyridine and cyclohexane with concomitant hydrogen evolution. Since the radical cation can selectively oxidize a cyclohexane to cyclohexyl radical, the cross-coupling between them proceeds with higher selectivity compared to that in the $\mathrm{TiO}_{2}$ photocatalysis under UV irradiation.
\end{abstract}

\section{Introduction}

Titanium oxide $\left(\mathrm{TiO}_{2}\right)$ is one of the most practical photocatalyst because of its abundance, chemical stability and strong oxidation ability, and thus many applications have been studied in both environmental and energy fields. ${ }^{1}$ In addition, many studies have been reported about organic synthesis by $\mathrm{TiO}_{2}$ photocatalyst. ${ }^{2-6}$ One of the problems of $\mathrm{TiO}_{2}$ photocatalyst is, however, difficulty in selective oxidation because of its strong oxidation ability that arises from the highly positive potential of its valence band. In this regard, several recent studies have developed photoexcitation of surface complex consisting of adsorbed molecules and the surface of $\mathrm{TiO}_{2}$ since they can be excited by visible light to promote various selective photooxidation reactions of various compounds such as alcohol,, 78 amine, ${ }^{9,10}$ and sulfides. ${ }^{11}$ The key of these systems is using the localized photoformed positive hole on the molecule to prevent undesired oxidation.

Although cross-coupling reactions have been studied well both in homogeneous and heterogeneous catalysis, ${ }^{12-14}$ no one had applied the surface complex systems to cross-coupling reactions. We recently discovered that when benzene adsorbed via $\pi$-interaction with the $\mathrm{TiO}_{2}$ surface is excited under visible light, a positive hole is generated in the benzene (a benzene radical cation) to promote direct photocatalytic dehydrogenative cross-coupling (DCC) reaction between benzene and cyclohexane to yield phenylcyclohexane and hydrogen. ${ }^{15}$

In the present study, we propose a new type of photoactive surface complex, which is an acid-base interacted heteroaromatic surface complex. As a simple example, we employed pyridine as an

\footnotetext{
a. Graduate School of Human and Environmental Studies, Kyoto University, Yoshida Nihonmatsu-cho, Sakyo-ku, Kyoto 606-8501, Japan.

b. Elements Strategy Initiative for Catalysts and Batteries (ESICB), Kyoto University, Kyotodaigaku-Katsura, Nishikyo-ku, Kyoto 615-8520, Japan.

*E-mail: yoshida.hisao.2a@kyoto-u.ac.jp

tElectronic Supplementary Information (ESI) available: Experimental details, information, and some results are shown in the ESI. See DOI: 10.1039/x0xx00000x
}

adsorbate and found for the first time that a DCC between pyridine and cyclohexane can take place with high selectivity (>99\% at $3.0 \%$ yield) through a novel and unique reaction mechanism, which starts from a visible light excitation of the surface complex consisting of pyridine and $\mathrm{TiO}_{2}$ surface.

\section{Experimental}

\subsection{Catalyst preparation}

Various $\mathrm{TiO}_{2}$ powder samples employed were donated by the Catalysis Society of Japan as JRC-TIO-8, JRC-TIO-14 (these are equivalent, anatase phase, $338 \mathrm{~m}^{2} \mathrm{~g}^{-1}$ ), JRC-TIO-6 (rutile phase, $100 \mathrm{~m}^{2} \mathrm{~g}^{-1}$ ), JRC-TIO-4 (a mixture of rutile and anatase phases, $50 \mathrm{~m}^{2} \mathrm{~g}^{-1}$ ) and JRC-TIO-2 (anatase phase, $18 \mathrm{~m}^{2} \mathrm{~g}^{-1}$ ). All metal-loaded $\mathrm{TiO}_{2}$ catalysts were prepared by a photodeposition method using the $\mathrm{TiO}_{2}$ powder and an aqueous methanol solution of an appropriate metal precursor such as $\mathrm{PdCl}_{2}$ (Kishida, 99\%), $\mathrm{H}_{2} \mathrm{PtCl}_{6} \cdot 6 \mathrm{H}_{2} \mathrm{O}$ (Wako, 99.9\%), and $\mathrm{RhCl}_{3} \cdot 3 \mathrm{H}_{2} \mathrm{O}$ (Kishida, 99\%), as follows. The $\mathrm{TiO}_{2}$ powder $(4.0 \mathrm{~g}$ ) was dispersed in ion-exchanged water $(300 \mathrm{ml})$ and was irradiated with a ceramic xenon lamp (PE300BUV) for $30 \mathrm{~min}$. Then, methanol $(100 \mathrm{ml})$ and the desired amount of the metal precursor solution were added to the suspension and the contents were magnetically stirred for $15 \mathrm{~min}$ without irradiation, followed by stirring in the light for $1 \mathrm{~h}$. It was then filtered off with suction, washed with ion-exchanged water, and dried at $323 \mathrm{~K}$ for $12 \mathrm{~h}$ so as to obtain the metal-loaded $\mathrm{TiO}_{2}$ photocatalysts. The catalysts were referred to as $\mathrm{M}(x) / \mathrm{TiO}_{2}$, where $\mathrm{M}$ indicates $\mathrm{Pt}, \mathrm{Pd}$, or $\mathrm{Rh}$, and $x$ indicates the loading amount in weight \%. After some experiments for optimization of photocatalyst (Table $\mathrm{S} 1-\mathrm{S} 3$ ), + a $\mathrm{Pt}(0.1) / \mathrm{TiO}_{2}$ photocatalyst was employed for the other experiments.

\subsection{Reaction test}

2.2.1 Materials. All of the chemicals employed for the photocatalytic reaction tests were of analytical grade and were used without further purification; pyridine (Nacalai Tesque, $99.7 \%$ ), cyclohexane (Nacalai Tesque, $99.5 \%$ ), 4-cyclohexylpyridine (Santa 
Table 1 Results of reaction tests under photoirradiation in the light of variously limited wavelength ${ }^{a}$
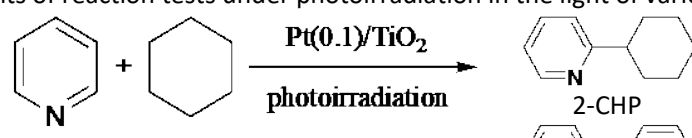
2-CHP

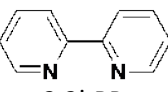

2,2'-BP

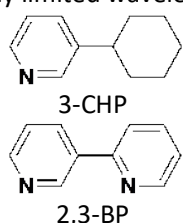

2,3-BP

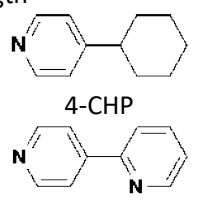

2,4-BP

\begin{tabular}{|c|c|c|c|c|c|c|c|c|c|c|c|c|c|c|}
\hline \multirow[t]{2}{*}{ Entry } & \multicolumn{2}{|c|}{$\begin{array}{l}\text { Substrate / } \\
\text { mmol }\end{array}$} & \multirow[t]{2}{*}{$\begin{array}{l}\lambda \\
/ \mathrm{nm}\end{array}$} & \multirow[t]{2}{*}{$\begin{array}{r}\text { Time } \\
/ \mathrm{h}\end{array}$} & \multicolumn{6}{|c|}{ Products $/ \mu \mathrm{mol}^{b}$} & \multirow[t]{2}{*}{$\begin{array}{l}\text { Conv. } \\
(\%)^{e}\end{array}$} & \multirow{2}{*}{$\begin{array}{c}\text { Yield of } \\
\text { CHPs } \\
(\%)^{f}\end{array}$} & \multicolumn{2}{|c|}{$\begin{array}{l}\text { Selectivity } \\
(\%)^{g}\end{array}$} \\
\hline & $\mathrm{C}_{5} \mathrm{H}_{5} \mathrm{~N}$ & $\mathrm{C}_{6} \mathrm{H}_{12}$ & & & CHPs & BPs & $\mathrm{BCH}$ & $\mathrm{CHOS}$ & $\begin{array}{l}\text { Tri- } \\
\text { coupled }^{c}\end{array}$ & $\mathrm{H}_{2}\left(\right.$ balance $\left.^{d}\right)$ & & & $S_{\mathrm{py}}$ & $S_{c y}$ \\
\hline 1 & 1.2 & 18 & $>350$ & 2 & 8.7 & 7.6 & 8.8 & 0.15 & 0.12 & $210(8.3)$ & 2.0 & 0.73 & 37 & 33 \\
\hline 2 & 1.2 & 18 & $>400$ & 2 & 5.5 & 1.3 & 0.47 & 0.17 & 0.0027 & $32(4.4)$ & 0.68 & 0.46 & 68 & 78 \\
\hline 3 & 1.2 & 18 & $>422$ & 2 & 1.2 & 0.11 & 0.011 & 0.065 & 0.00 & $14(11)$ & 0.12 & 0.10 & 83 & 91 \\
\hline 4 & 0.31 & 18 & $>422$ & 2 & 1.4 & 0.0034 & 0.033 & 0.00 & 0.00 & $17(12)$ & 0.45 & 0.44 & $>99$ & 94 \\
\hline
\end{tabular}

${ }^{a}$ Reaction conditions: pyridine $(0.10 \mathrm{~mL}, 1.2 \mathrm{mmol})$ and cyclohexane $(1.9 \mathrm{~mL}, 18 \mathrm{mmol})$ with the $\mathrm{Pt}(0.1) / \mathrm{TiO}_{2}$ photocatalyst $(0.1 \mathrm{~g})$ were used, the light intensity was $130 \mathrm{~mW} \mathrm{~cm}^{-2}$ measured at $395 \pm 35 \mathrm{~nm}$ in wavelength. ${ }^{b} \mathrm{CHPs}$ : total amount of 2-CHP, 3-CHP, and 4-CHP. BPs: total amount of 2,2'-BP, 2,3'$\mathrm{BP}$, and 2,4'-BP. CHOs: total amount of cyclohexanone and cyclohexanol. ${ }^{c}$ The mass numbers were 238 and $243 .{ }^{d} \mathrm{H}_{2}$ balance was calculated as: [Actual amount of $\left.\mathrm{H}_{2}(\mu \mathrm{mol})\right] /$ [Expected amount of $\mathrm{H}_{2}(\mathrm{CHPs}+\mathrm{BPs}+\mathrm{BCH}+2 \times$ Tri-coupled) $(\mu \mathrm{mol})]$. ${ }^{e}$ Conversion of pyridine was calculated as: [100 $\times(\mathrm{CHPs}+2$ $\times \mathrm{BHC})(\mu \mathrm{mol})] /\left[\mathrm{C}_{5} \mathrm{H}_{5} \mathrm{~N}(\mu \mathrm{mol})\right] .{ }^{f}$ Yield of $\mathrm{CHPs}$ based on the introduced pyridine. ${ }^{g} \mathrm{DCC}$ selectivity. Selectivity based on the products from pyridine was calculated as: $S_{p y}=[100 \times \mathrm{CHPs}(\mu \mathrm{mol})] /[(\mathrm{CHPs}+2 \times \mathrm{BPs})(\mu \mathrm{mol})] ;$ selectivity based on cyclohexane as: $S_{\mathrm{cy}}=[100 \times \mathrm{CHPs}(\mu \mathrm{mol})] /[(\mathrm{CHPs}+2 \times \mathrm{BHC}+\mathrm{CHOs})$ $(\mu \mathrm{mol})]$.

Cruz Biotechnology), 2,2'-bipyridyl (Wako Pure Chemicals, $99.5 \%$ ), 2,3'-bipyridine (Sankyo Chemical Industry), 2,4'-bipyridyl (Wako Pure Chemicals, $97 \%$ ), bicyclohexyl (Tokyo Kasei Kogyo, >99 \%), cyclohexanone (Nacalai Tesque, $97 \%$ ), cyclohexanol (Kishida Chemical, $>99 \%$ ), pyridine- $d_{5}$ (Euriso-Top, $99.5 \%$ ) and cyclohexane$d_{12}$ (Sigma-Aldrich, 99.6\%).

Most of the authentic samples were purchased to make the GCMS calibration curve for the quantitative analysis of the products in the reaction experiments, while an authentic sample of the main cross-coupling product from pyridine and cyclohexane, 2cyclohexylpyridine (2-CHP), was synthesized in the manner reported in the literature. ${ }^{16}$ For quantification of 3-cyclohexylpyridine (3-CHP) and tri-coupled products, the calibration curve of 2-CHP was tentatively used.

2.2.2 Procedure for the reaction tests. Before a photocatalytic reaction test, the $\mathrm{M}(x) / \mathrm{TiO}_{2}$ sample $(0.1 \mathrm{~g})$ in a Pyrex glass tube (20 $\mathrm{mL}$ ) was subjected to pre-treatment for 30 min under the light from the xenon lamp to clean its surface. Then, the reactants were added into the test tube, followed by sealing of the reactor with a rubber septum and bubbling argon for $10 \mathrm{~min}$. The reaction mixture was irradiated by using the $300 \mathrm{~W}$ xenon lamp with stirring for the desired reaction time at room temperature. The irradiation wavelength was limited by a cut-off filter. After the irradiation, $0.5 \mathrm{~mL}$ of the gaseous phase was collected by an air-tight syringe and analyzed by a GC-TCD (Shimadzu, GC-8A). The reaction mixture in the liquid phase was sampled by a syringe with a PTFE filter to remove the $\mathrm{M}(x) / \mathrm{TiO}_{2}$ sample, and then analyzed by a GC-MS (Shimadzu, GCMS-QP2020).

2.2.3 Mechanistic studies. In order to get an insight into the reaction mechanism, some photocatalytic reaction tests for reaction kinetic study were performed with isotopically labelled compounds such as deuterated pyridine and deuterated cyclohexane.

Temperature controlled photocatalytic reactions were also carried out, where a beaker was used as a water bath to keep the desired reaction temperature in the range of 310-328 K. A mixture of pyridine $(0.61 \mathrm{mmol})$ and cyclohexane $(9.0 \mathrm{mmol})$ was used as the substrates.

\subsection{Characterization of catalysts}

UV-vis spectra of the powder samples were recorded in a diffuse reflectance mode. For the measurements the samples were prepared as follows. A mixture of $\mathrm{TiO}_{2}$ (JRC-TIO-14, $0.3 \mathrm{~g}$ ) and $\mathrm{BaSO}_{4}$ $(2.97 \mathrm{~g})$ was well mixed in a mortar for $15 \mathrm{~min}$ so as to give a 100 times diluted $\mathrm{TiO}_{2}$ sample. For the samples with an adsorbate, $50 \mu \mathrm{L}$ of pyridine or cyclohexane was added to $0.15 \mathrm{~g}$ of the diluted samples or $\mathrm{BaSO}_{4}$, followed by $30 \mathrm{~min}$ of stirring. Then, desired amount of the sample (typically $0.13 \mathrm{~g}$ ) was taken into the cell so as to fix the amount of $\mathrm{TiO}_{2}$ in the samples and the spectrum was measured using a UV-vis spectrophotometer (JASCO V-570) equipped with an integrating sphere, where $\mathrm{BaSO}_{4}$ was used as a reference.

\section{Results and discussion}

\subsection{Effect of irradiation wavelength}

Under the light including both UV and visible light $(\lambda>350 \mathrm{~nm}$, Table 1, entry 1$)$, the reaction took place to give 2-cyclohexylpyridine (2-CHP), 3-cyclohexylpyridine (3-CHP), and 4-cyclohexylpyridine (4$\mathrm{CHP}$ ) as the DCC products (CHPs), as well as the homo-coupling products from pyridine (bipyridyls (BPs): 2-BP, 3-BP, and 4-BP) and cyclohexane (bicyclohexyl: $\mathrm{BCH}$ ), and very small amount of tricoupled products whose mass numbers were 238 and 243, i.e., possibly formed from two pyridine and one cyclohexane and from one pyridine and two cyclohexane. Tiny amounts of cyclohexanone and cyclohexanol were also formed, which would be produced in the photocatalytic oxidation by the surface hydroxyl group or adsorbed water as reported. ${ }^{17}$ The reaction did not proceed in the dark or in the absence of the photocatalyst. The selectivity to the DCC products was low such as $37 \%$ and $33 \%$ based on the products from pyridine $\left(S_{\text {py }}\right)$ and cyclohexane $\left(S_{\mathrm{cy}}\right)$, respectively, in this irradiation condition, which originated from the formation of undesired products such as 
$\mathrm{BPs}, \mathrm{BCH}$ and so on. The unselective formation of them suggests that both pyridyl $\left(\mathrm{C}_{5} \mathrm{H}_{4} \mathrm{~N}\right)$ and cyclohexyl $\left(\mathrm{C}_{6} \mathrm{H}_{11}\right)$ radicals were formed by the photocatalytic hole oxidation of these reactants on the UV-lightactivated $\mathrm{TiO}_{2}$ photocatalyst, followed by their successive radical coupling.

In contrast, under visible light irradiation $(\lambda>400$ and $422 \mathrm{~nm}$ ), the selectivity to the DCC products was higher (Table 1, entries 2 and $3)$, especially under the further limited light irradiation $(\lambda>422 \mathrm{~nm})$ $S_{\mathrm{py}}$ and $S_{\mathrm{cy}}$ were $83 \%$ and $91 \%$, respectively (Table 1 , entry 3 ), although the production rates were lower due to the limitation of the light compared with the case including UV light. Lower concentration of pyridine provided higher selectivity $\left(S_{\mathrm{py}}>99 \%\right)$ due to a suppression of homo-coupling of pyridine (Table 1, entry 4 ) and the selectivity maintained for a long time even after the yield reached to $3.0 \%$ (Table 1, entry 5 and Figure 1). This indicates the presence of different reaction mechanism from that under the irradiation including UV light. A decrease in the slope of the product yield curve with time might be due to successive reactions of the products or adsorption of the products disturbing the surface active sites. Additionally, it was found that the regioselectivity of CHPs was almost the same in most cases regardless of the irradiation wavelength, i.e., about $65 \%$ of $2-\mathrm{CHP}, 10 \%$ of $3-\mathrm{CHP}$, and $25 \%$ of 4 $\mathrm{CHP}$, which is almost consistent with the $\mathrm{C}-\mathrm{H}$ bond dissociation energy (BDE) of pyridine (Table S4, $439.3 \mathrm{~kJ} \mathrm{~mol}^{-1}$ for the site 2 and $468.6 \mathrm{~kJ} \mathrm{~mol}^{-1}$ for the sites 3 and 4)..$^{18}$

We also observed enough amount of hydrogen production, confirming that the reaction underwent dehydrogenatively. Although it was difficult to determine the accurate amount in all the reaction tests, the amount was larger than that expected from those of the detected organic products as is clear in the large value in the $\mathrm{H}_{2}$ balance. This could be due to the presence of undetected stronglyadsorbed products on the catalyst surface or the progress of side reactions such as successive reactions of the products to larger oligomers.

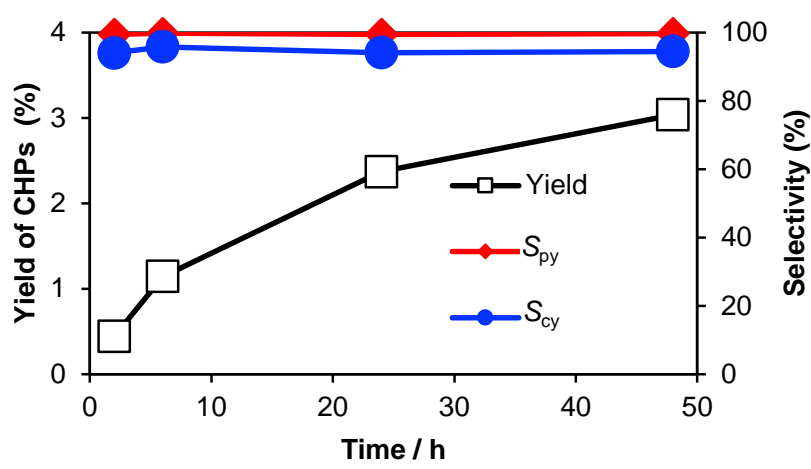

Fig. 1 Time course of the cross-coupling reaction between pyridine and cyclohexane. Pyridine $(0.025 \mathrm{~mL}, 0.31 \mathrm{mmol})$ and cyclohexane $(1.975 \mathrm{~mL}$, $18 \mathrm{mmol}$ ) with the $\mathrm{Pt}(0.1) / \mathrm{TiO}_{2}$ photocatalyst $(0.1 \mathrm{~g})$ were used. The irradiation wavelength was $\lambda>422 \mathrm{~nm}$ in wavelength. See the caption of Table 1 for the definitions for the DCC selectivities, $S_{\mathrm{py}}$ and $S_{\mathrm{cy}}$.

\subsection{Diffuse reflectance UV-vis spectroscopy}

As well known, the $\mathrm{TiO}_{2}$ photocatalyst itself cannot work under visible light irradiation. To investigate the origin of the photoexcitation under visible light, we carried out diffuse reflectance UV-vis spectroscopy. ${ }^{+}$The powder $\mathrm{TiO}_{2}$ samples were diluted by $\mathrm{BaSO}_{4}$ to decrease the absorption for accurate discussion. Fig. $2 \mathrm{~A}$ shows DR UV-vis spectra of the $\mathrm{TiO}_{2}$ sample, the pyridine adsorbed $\mathrm{TiO}_{2}$ sample, the pyridine adsorbed $\mathrm{BaSO}_{4}$, and the difference spectrum of the pyridine adsorbed samples, and Fig. $2 \mathrm{~B}$ shows their enlarged view and the transmission spectra of various cut-off filters $(\lambda>350,400$, and $422 \mathrm{~nm})$ used in the reaction tests.

The spectrum of the pyridine adsorbed $\mathrm{BaSO}_{4}$ (Fig. 2Ac) was almost similar to the absorption spectrum of molecular pyridine in a cyclohexane solution (Fig. S1a). Cyclohexane exhibited no absorption in the spectrum (Fig. S1b). The spectrum of cyclohexane adsorbed sample was almost same with $\mathrm{TiO}_{2}$ itself (Fig. S2C). Thus, the absorption band at $250-300 \mathrm{~nm}$ in wavelength shown in Fig. $2 \mathrm{Ac}$ is assignable to pyridine molecule adsorbed physically or that in liquid phase.

It is notable that the pyridine adsorbed $\mathrm{TiO}_{2}$ sample exhibited a large absorption band (Fig. 2Ab) and the absorption edge was extended to longer than $400 \mathrm{~nm}$ (Fig. $2 \mathrm{Bb}$ ) while $\mathrm{TiO}_{2}$ itself only absorbed UV light less than $380 \mathrm{~nm}$ (Figs. 2Aa and 2Ba). Comparison of the spectra of the pyridine adsorbed samples with and without $\mathrm{TiO}_{2}$ (Figs. $2 \mathrm{Ab}$ and $2 \mathrm{Ac}$ ) confirmed that the pyridine-adsorbed $\mathrm{TiO}_{2}$ exhibited a new broad absorption band centered around $300 \mathrm{~nm}$, shown as the difference spectrum (Fig. 2Ad), that should appear as a result of the interaction between pyridine and $\mathrm{TiO}_{2}$. It can be proposed that this absorption band is attributed to LMCT excitation of the surface complex of the adsorbed pyridine and the $\mathrm{TiO}_{2}$ surface as with those reported other adsorbates such as catechol, alcohol ${ }^{8}$ and amine. ${ }^{9,10}$ Pyridine as a base molecule can be adsorbed by an acid-base interaction on the surface Lewis acid sites ( $\mathrm{Ti}^{4+}$ cation) on $\mathrm{TiO}_{2}$ surface. ${ }^{19}$ The present LMCT would occur in the $\mathrm{N}-\mathrm{Ti}$ coordination bond in analogy with other amine- $\mathrm{TiO}_{2}{ }^{9,10}$ and $\mathrm{NH}_{3}-$ $\mathrm{TiO}_{2}{ }^{20}$ surface complex systems.

If the LMCT transition occurs from HOMO of the adsorbed pyridine to the conduction band of $\mathrm{TiO}_{2}$, which is not a sharp energy distribution but a rather wide band, its spectrum shape should be cliff-shaped as with that of $\mathrm{TiO}_{2}$ absorption band. However, the shape is bell-shaped. Thus, it is suggested that the LMCT transition occurs not to the conduction band of $\mathrm{TiO}_{2}$ but to the localized $3 \mathrm{~d}$ orbital of the surface Ti cation interacted with pyridine. The excited electron finally would be transferred to the conduction band of $\mathrm{TiO}_{2}$, which is supported by the Pt-promoting hydrogen production as mentioned later. Furthermore, since HOMO of pyridine consists of mainly the lone pair of nitrogen, ${ }^{21}$ an electron would be excited from the lone pair of nitrogen to the Ti cation. This means that the excited state of the surface complex would be a radical cation $\left(\mathrm{Ti}^{-} \mathrm{C}_{5} \mathrm{H}_{5} \mathrm{~N}^{\cdot+}\right)$ as shown in the scheme in Fig. 2A. The LMCT absorption band was extended to longer than $400 \mathrm{~nm}$ in wavelength (Fig. 2Bd). Thus, it is clear that the first photoactivated species in the reaction system under visible light irradiation is related to not cyclohexane nor $\mathrm{TiO}_{2}$ itself but the adsorbed pyridine on the $\mathrm{TiO}_{2}$ surface, in other words, the DCC reaction under visible light starts with the generation of pyridine radical cation through the LMCT excitation of the acid-base interacted surface complex on the $\mathrm{TiO}_{2}$ surface. 

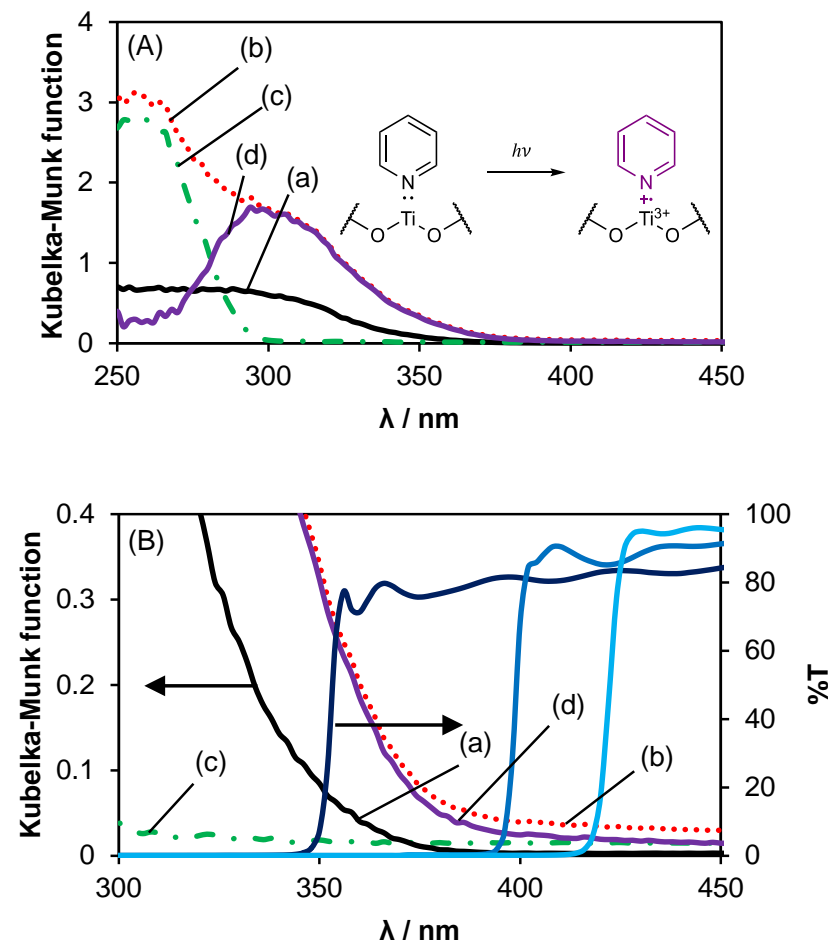

Fig. 2 (A) DR UV-vis spectra of the $\mathrm{BaSO}_{4}$ diluted $\mathrm{TiO}_{2}$ sample (a), the pyridine adsorbed diluted $\mathrm{TiO}_{2}$ sample (b), $\mathrm{BaSO}_{4}$ with pyridine (c) and the difference spectrum of $b-c(d)$. Embedded scheme represents the possible photoexcitation of the pyridine- $\mathrm{TiO}_{2}$ surface complex. (B) The enlarged view of Fig. 1A with the transmission spectra of the cut-off filters $(\lambda>350$, 400 , and $422 \mathrm{~nm}$ ) used in reaction tests.

\subsection{Isotopic experiment}

In order to elucidate the difference in the reaction mechanism under the alternative irradiation conditions, isotope experiments were carried out. Table 2 shows the results. In the presence of UV light, the yields of CHPs and $\mathrm{BCH}$ in the reaction between pyridine and cyclohexane- $d_{12}$ were smaller than those in the reaction with normal reagents (Table 2, entries 1 and 2), where the $k_{H} / k_{D}$ values were more than unity, i.e., 1.8 and 3.7 for $\mathrm{CHPs}$ and $\mathrm{BCH}$, respectively (kinetic isotope effects, KIEs). Thus, the rate determining step (RDS) in their formation reactions under the light including UV light should be the $\mathrm{C}-\mathrm{H}$ bond cleavage in cyclohexane. Similarly, the KIE for BPs in the reaction with pyridine- $d_{5}$ (entry $3, k_{\mathrm{H}} / k_{\mathrm{D}}=2.1$ ) evidenced that the $\mathrm{C}-\mathrm{H}$ bond cleavage in pyridine is the RDS of the homo-coupling of pyridine. The formation of both BPs and $\mathrm{BCH}$ and these KIEs propose a radical-radical coupling mechanism for the formation of CHPs, in which both pyridine and cyclohexane were activated to become their radical species before their coupling.

In contrast, the $k_{\mathrm{H}} / k_{\mathrm{D}}$ value was less than unity for the homocoupling of the non-deuterated compound ( 0.68 for BPs in entry 2 and 0.85 for $\mathrm{BCH}$ in entry 3 ), which can be recognized as the inverse KIEs. In the proposed radical coupling mechanism, both two molecules should be oxidized by the photogenerated holes to become their radical species, meaning that the two oxidation processes competitively consume the limited number of the holes. Therefore, since $\mathrm{C}-\mathrm{D}$ bond is stronger than $\mathrm{C}-\mathrm{H}$ bond, the replacement by the deuterated compound would slow down
Table 2 Results of isotope experiments ${ }^{a}$

\begin{tabular}{lllllll}
\hline Entry & $\lambda / \mathrm{nm}$ & $\begin{array}{l}\text { Deuterated } \\
\text { compound }\end{array}$ & & \multicolumn{4}{l}{ Product $/ \mu \mathrm{mol},\left(k_{\mathrm{H}} / k_{\mathrm{D}}\right)^{b}$} & \\
\cline { 4 - 7 } & & & $\mathrm{CHPs}$ & $\mathrm{BPs}$ & $\mathrm{BCH}$ & \\
\hline 1 & $>350$ & - & 5.4 & 5.0 & 5.2 & \\
2 & & $\mathrm{C}_{6} \mathrm{D}_{12}$ & $3.2(1.8)$ & $7.4(0.68)$ & 1.4 & $(3.7)$ \\
3 & & $\mathrm{C}_{6} \mathrm{D}_{5} \mathrm{~N}$ & $6.2(0.87)$ & $2.4(2.1)$ & 6.1 & $(0.85)$ \\
4 & $>400$ & - & 2.9 & 1.2 & & 0.33 \\
5 & & $\mathrm{C}_{6} \mathrm{D}_{12}$ & $1.4(2.1)$ & $1.9(0.63)$ & $0.066(5.0)$ \\
6 & & $\mathrm{C}_{6} \mathrm{D}_{5} \mathrm{~N}$ & $2.8(1.0)$ & $0.55(2.2)$ & $0.37(0.89)$
\end{tabular}

${ }^{a}$ Reaction conditions: pyridine $(0.05 \mathrm{~mL}, 0.62 \mathrm{mmol})$ and cyclohexane $(0.95 \mathrm{~mL}, 9.0$ $\mathrm{mmol}$ ) with the $\mathrm{Pt}(0.1) / \mathrm{TiO}_{2}$ photocatalyst $(50 \mathrm{mg}$ ) were used, the reaction time was $1 \mathrm{~h}$, and light intensity was $160 \mathrm{~mW} \mathrm{~cm}-2$ measured at $395 \pm 35 \mathrm{~nm}$ in wavelength. ${ }^{b}$ The values in parentheses: $k_{\mathrm{H}} / k_{\mathrm{D}}=$ (amount of the products in entry 1 ) / (that in entry 2 or 3 ) or (that in entry 4 ) / (that in entry 5 or 6 ).

its oxidation rate and instead enhance the oxidation of the other compound, resulting these inverse KIEs for these homo-coupling reactions. This explanation can also be applied to the inverse KIE for CHPs with pyridine- $d_{5}$ (entry $3, k_{\mathrm{H}} / k_{\mathrm{D}}=0.87$ ), i.e., the use of pyridine$d_{5}$ would accelerate the oxidation of cyclohexane, which is the RDS in the DCC, and as a result, the formation rate of CHPs was increased.

Considering that both pyridine and cyclohexane are oxidized by holes, it may seem unreasonable that the RDS of the DCC is the $\mathrm{C}-\mathrm{H}$ bond cleavage in cyclohexane since the amount of cyclohexane is excess and the $\mathrm{C}-\mathrm{H}$ bond cleavage in cyclohexane is easier than in pyridine in terms of $\mathrm{C}-\mathrm{H}$ BDE (Table S4, $416.3 \mathrm{~kJ} \mathrm{~mol}^{-1}$ for cyclohexane and $439.3 \mathrm{~kJ} \mathrm{~mol}^{-1}$ for site 2 of pyridine)..$^{18}$ However, this can be explained by the availability of holes on the $\mathrm{TiO}_{2}$ surface as follows. In the control experiments, the amount of $\mathrm{BCH}$ decreased drastically when the same amount of pyridine was introduced (Table S5), while that of BPs decreased slightly even when cyclohexane was coexistent, meaning that pyridine is preferentially absorbed and oxidized on the $\mathrm{TiO}_{2}$ surface compared with cyclohexane. Thus, the hole oxidation of cyclohexane was the RDS in the DCC even in this condition. Based on these results, it is clarified that, in the presence of UV light, the DCC reaction starts from the hole oxidation of each molecule to form the radical species followed by a radical coupling.

Under visible light irradiation, the hole oxidation by the $\mathrm{TiO}_{2}$ photocatalyst less occurs. In this condition, the amounts of homocoupling products were small. The KIEs were observed for yielding CHPs and BCH in the reaction with cyclohexane- $d_{12}$ (entry $5, k_{\mathrm{H}} / k_{\mathrm{D}}=$ 2.1 and 5.0, respectively), which evidenced that the RDS for their formation reactions under visible light is also the $\mathrm{C}-\mathrm{H}$ bond cleavage in cyclohexane as well as the case including UV light. The change in the amount of $\mathrm{BCH}$ in entry 4 and 6 was too small to discuss. Importantly, almost no change was observed in the yield of CHPs when pyridine- $d_{5}$ was used (entry $6, k_{H} / k_{\mathrm{D}}=1.0$ for CHPs). This clearly different trend from that in the presence of UV light indicates that the reaction mechanism should be different, i.e., the oxidation of pyridine and cyclohexane was not competitive under visible light irradiation.

As mentioned above, the DR UV-vis spectroscopy revealed that pyridine forms the surface complex with $\mathrm{TiO}_{2}$ to be photoexcited even under visible light while cyclohexane does not. Along with the LMCT excitation, pyridine radical cation is generated, and it would be able to react with pyridine or cyclohexane molecules (eqs. 1 and 2). From a calculation of the change of free energy in these reactions 
(Fig. S3), + the reaction with cyclohexane (eq. 2) was found to be more thermodynamically favorable than that with pyridine (eq. 1). It is also confirmed that a direct deprotonation from the pyridine cation radical (eq. 3) is less thermodynamically favored compared with the reaction with cyclohexane (eq. 2). Moreover, the amount of cyclohexane is in excess of that of pyridine (typically, the molar ratio of cyclohexane to pyridine was 14.5). Thus, pyridine radical cation would go through the reaction with cyclohexane to give cyclohexyl radical rather than that with pyridine or the deprotonation.

Successively, the DCC reaction would take place in a radical addition-elimination mechanism, where the cyclohexyl radical attacks to pyridine molecule to form an $\mathrm{sp}^{3}$-centered transition state and a hydrogen radical is eliminated from it. In this case, it seems reasonable that the cleavage of C-D bond in pyridine- $d_{5}$ moiety of this transition state would not be the RDS (entry $6, k_{H} / k_{D}=1.0$ for CHPs). The inverse KIE for BPs yield in the reaction with cyclohexane$d_{12}$ (entry $5, k_{\mathrm{H}} / k_{\mathrm{D}}=0.63$ ) could be due to an increase in the competitive formation of pyridyl radical via the reaction between the radical cation and pyridine molecules (eq. 1), or a deprotonation of the cation radical (eq. 3), which might be promoted by the other species such as surface hydroxyl group (eq. 4).

$$
\begin{aligned}
\mathrm{C}_{5} \mathrm{H}_{5} \mathrm{~N}^{\cdot+}+\mathrm{C}_{5} \mathrm{H}_{5} \mathrm{~N} & \rightarrow \mathrm{C}_{5} \mathrm{H}_{5} \mathrm{~N}+{ }^{\cdot} \mathrm{C}_{5} \mathrm{H}_{4} \mathrm{~N}+\mathrm{H}^{+} \\
\mathrm{C}_{5} \mathrm{H}_{5} \mathrm{~N}^{\bullet+}+\mathrm{C}_{6} \mathrm{H}_{12} & \rightarrow \mathrm{C}_{5} \mathrm{H}_{5} \mathrm{~N}+{ }^{\cdot} \mathrm{C}_{6} \mathrm{H}_{11}+\mathrm{H}^{+} \\
\mathrm{C}_{5} \mathrm{H}_{5} \mathrm{~N}^{\bullet+} & \rightarrow{ }^{\cdot} \mathrm{C}_{5} \mathrm{H}_{4} \mathrm{~N}+\mathrm{H}^{+} \\
\mathrm{C}_{5} \mathrm{H}_{5} \mathrm{~N}^{\cdot+}+\mathrm{OH}_{\text {sur }} & \rightarrow{ }^{\cdot} \mathrm{C}_{5} \mathrm{H}_{4} \mathrm{~N}+{ }^{+} \mathrm{OH}_{2, \text { sur }}
\end{aligned}
$$

\subsection{Temperature control test}

In this system, without the deposited metal nanoparticles, the bare $\mathrm{TiO}_{2}$ photocatalyst was less active (Table S2, entry 1 ). The addition of $\mathrm{Pt}$ on the $\mathrm{TiO}_{2}$ photocatalyst enhanced the reaction rate (Table S2, entry 2), and Pt was most suitable among the metal cocatalyst tested (Table S2, entries 3-5). It is well accepted that metal nanoparticles loaded on photocatalysts are considered to act as an electron receiver to promote charge separation in the excited photocatalyst, ${ }^{22-25}$ while it has been noticed that in some cases they can also work as a metal catalyst, e.g., for $\mathrm{C}-\mathrm{H}$ activation of hydrocarbons. ${ }^{26}$ Thus, we carried out temperature control tests under the alternative irradiation conditions to elucidate the possibility of Pt metal catalysis in the DCC between pyridine and cyclohexane. Fig. 3 showed the results in the pseudo-Arrhenius plots for the production rate of CHPs in the reactions with a pristine or Pt loaded sample under photoirradiation of UV and visible light (Fig. 3A) or only visible light (Fig. 3B). The yield of CHPs increased with increasing the reaction temperature regardless of the irradiation condition and the sample. The plots for each reaction system were almost in a straight line. The thermal activation energies were calculated from the slopes of the approximation lines and summarized in Table 3. The activation energies for the DCC reaction with the pristine and Pt loaded samples were almost the same values, i.e., 41 and $40 \mathrm{~kJ} \mathrm{~mol}^{-1}$ under UV and visible light (Table 3, entries 1 and 2) and 22 and $28 \mathrm{~kJ} \mathrm{~mol}^{-1}$ under visible light (Table 3, entries 3 and 4). This indicates that Pt did not contribute to the thermal activation process, i.e., the reaction takes place without Pt metal catalysis. Also, the Pt loaded sample showed better activity than the pristine sample for the reaction in both irradiation condition (Fig. 3, $\mathrm{A}$ and $\mathrm{B})$. This means that the Pt nanoparticles contribute to the higher reaction rate except for the thermal catalysis. Therefore, the role of $\mathrm{Pt}$ should be the electron receiver to suppress the recombination of electrons and holes under both irradiation conditions.

The activation energies obtained under UV and visible light (Table 3, entries 1 and 2) was larger than that under visible light (Table 3, entries 3 and 4). This means that the dark process requires more energy in the $\mathrm{TiO}_{2}$ photocatalysis as a main reaction under UV light. It could be due to the difference in the place where holes are generated. Since holes are generated in bulk $\mathrm{TiO}_{2}$ under the light including UV light, they need thermal energy to migrate to the surface before the reaction with the substrates. On the other hand, under visible light, holes are generated in the adsorbed pyridine to form the radical cation on the $\mathrm{TiO}_{2}$ surface. This means that the holes can be directly used without migration. This would be the reason why the thermal energy required under visible light was smaller than that under the light of UV and visible.
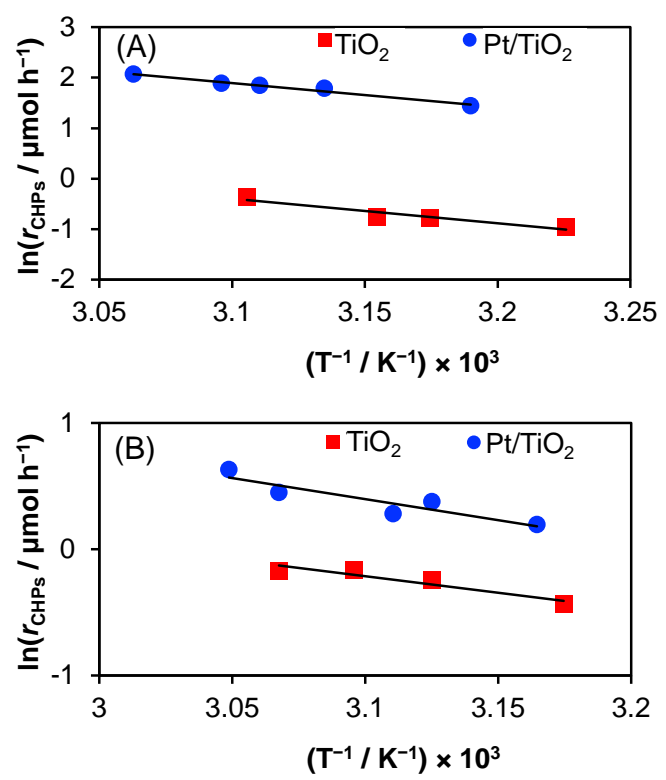

Fig. 3 Pseudo-Arrhenius plots of the CHPs formation rate $\left(r_{\mathrm{CHPs}}\right)$ for the temperature controlled reactions between pyridine and cyclohexane with a pristine $\mathrm{TiO}_{2}$ (red squares) or $\mathrm{Pt}(0.1) / \mathrm{TiO}_{2}$ (blue circles) under UV and

\begin{tabular}{|c|c|c|c|}
\hline Entry & $\lambda / \mathrm{nm}$ & Photocatalyst & $E_{\mathrm{a}, \mathrm{CHPs}} / \mathrm{kJ} \mathrm{mol}^{-1}$ \\
\hline 1 & $>350$ & $\mathrm{TiO}_{2}$ & 41 \\
\hline 2 & & $\mathrm{Pt}(0.1) / \mathrm{TiO}_{2}$ & 40 \\
\hline 3 & $>400$ & $\mathrm{TiO}_{2}$ & 22 \\
\hline 4 & & $\mathrm{Pt}(0.1) / \mathrm{TiO}_{2}$ & 28 \\
\hline
\end{tabular}
visible light (A) and visible light (B). The amount of CHPs at the initial stage with low conversion was used for the calculation of the formation rate of CHPs. 


\subsection{Tentative reaction mechanism}

Based on all of the results, we propose tentative reaction mechanism as follows.

Under the irradiation including UV light (Fig. 4A), the $\mathrm{TiO}_{2}$ photocatalyst is excited to give the photogenerated electrons and holes in the conduction band and the valence band, respectively. The electrons were transferred to the Pt nanoparticles while the holes were trapped on the $\mathrm{TiO}_{2}$ surface (scheme i). Pyridine and cyclohexane are competitively oxidized by the holes to the corresponding radical species (schemes ii and iii). Then, the radicalradical coupling of these radicals affords the DCC products (CHPs, scheme iv) as well as the homo-coupling products (BPs and $\mathrm{BCH}$, schemes $v$ and vi). Protons are reduced by the electrons on the Pt cocatalyst to give a molecular hydrogen (scheme vii). This is a twophoton process (Fig. 4A). Role of Pt cocatalyst is a charge separator to suppress the recombination of the electrons and holes. Although the visible light excitation of the surface pyridine complexes should also occur at the same time and partially contribute to the DCC product formation, the $\mathrm{TiO}_{2}$ photocatalysis mentioned above would be predominant.

On the other hand, under visible light irradiation (Fig. 4B), the surface complex consisting of adsorbed pyridine and Ti cation, in which the acid-base $\mathrm{N}-\mathrm{Ti}$ coordination bond is formed by using a lone pair of nitrogen (scheme viii), is photoexcited to generate an excited electron from the lone pair and a hole remains in a pyridine radical cation (scheme ix). The electron is injected to the conduction band of $\mathrm{TiO}_{2}$ via the surface $\mathrm{Ti}$ cation, followed by a transfer to the deposited Pt nanoparticles. The pyridine radical cation (the hole) oxidizes cyclohexane to form cyclohexyl radical and a proton (scheme $x$ ), and the DCC proceeds between the cyclohexyl radical and the pyridine molecule in a radical addition-elimination process, i.e., the attack of the radical species to the pyridine to form an $\mathrm{sp}^{3}$ centered transition state and an elimination of hydrogen radical from the transition state (scheme $x i$ and xii). The hydrogen elimination from the transition state would be more preferred than other possibilities, for example, although one may consider another possibility that the second photon absorption may occur on the $\mathrm{sp}^{3}$ centered radical species to release a proton, the photoexcitation of the transition state is usually difficult. Although the possibility that the other species may facilitate the release of the hydrogen radical is not excluded, the scheme xii itself would be thermodynamically favorable since the molecule regain its aromaticity by releasing a $\mathrm{H}$ radical. Apart from the LMCT sites, the proton is reduced by the electron on the Pt nanoparticle, followed by the reaction with the hydrogen radical to give a molecular hydrogen (scheme xiii).

The reaction under visible light should be a one-photon process (Fig. 4B). In this mechanism, the generation of pyridine radical cation takes place instead of hole oxidation of pyridine, and the pyridine radical cation is responsible for the oxidation of cyclohexane. Since thus produced cyclohexyl radical should be close to the pyridine when it was formed (scheme $x$ ), the collision frequency between the two (scheme xi) would be large, and this could explain the suppression of homo-coupling of cyclohexane. Pt co-catalyst works as the electron receiver to suppress the recombination of the electrons and the cation radical.

\section{In the presence of UV light}

$$
\begin{aligned}
& \mathrm{Pt} / \mathrm{TiO}_{2}+h v \rightarrow \mathrm{e}^{-} \mathrm{Pt}^{+}+\mathrm{h}^{+}{ }_{\mathrm{TiO} 2} \\
& \mathrm{C}_{5} \mathrm{H}_{5} \mathrm{~N}+\mathrm{h}^{+} \mathrm{TiO}_{\mathrm{O}} \rightarrow{ }^{-} \mathrm{C}_{5} \mathrm{H}_{4} \mathrm{~N}+\mathrm{H}^{+} \\
& \mathrm{C}_{6} \mathrm{H}_{12}+\mathrm{h}^{+}{ }_{\mathrm{TiO} 2} \rightarrow{ }^{\circ} \mathrm{C}_{6} \mathrm{H}_{11}+\mathrm{H}^{+} \\
& \cdot{ }^{\circ} \mathrm{C}_{5} \mathrm{H}_{4} \mathrm{~N}+{ }^{\circ} \mathrm{C}_{6} \mathrm{H}_{11} \rightarrow \mathrm{C}_{11} \mathrm{H}_{10} \mathrm{~N} \text { (CHPs) } \\
& \cdot{ }^{\circ} \mathrm{C}_{5} \mathrm{H}_{4} \mathrm{~N}+{ }^{\circ} \mathrm{C}_{5} \mathrm{H}_{4} \mathrm{~N} \rightarrow \mathrm{C}_{10} \mathrm{H}_{8} \mathrm{~N}_{2} \text { (BPs) } \\
& \text { - } \mathrm{C}_{6} \mathrm{H}_{11}+{ }^{\circ} \mathrm{C}_{6} \mathrm{H}_{11} \rightarrow \mathrm{C}_{12} \mathrm{H}_{22}(\mathrm{BCH}) \\
& 2 \mathrm{H}^{+}+\mathrm{e}^{-} \mathrm{pt} \rightarrow \mathrm{H}_{2}
\end{aligned}
$$

\section{Under visible light}

$\mathrm{C}_{5} \mathrm{H}_{5} \mathrm{~N}+\mathrm{TiO}_{2} \rightarrow \mathrm{C}_{5} \mathrm{H}_{5} \mathrm{~N}-\mathrm{TiO}_{2}$ (surface complex)

$\mathrm{C}_{5} \mathrm{H}_{5} \mathrm{~N}-\mathrm{TiO}_{2}$ (surface complex) $\rightarrow \mathrm{C}_{5} \mathrm{H}_{5} \mathrm{~N}^{\bullet+}+\mathrm{TiO}_{2}\left(\mathrm{e}^{-} \mathrm{Pt}_{\mathrm{t}}\right)$

$$
\begin{gathered}
\mathrm{C}_{5} \mathrm{H}_{5} \mathrm{~N}^{\cdot+}+\mathrm{C}_{6} \mathrm{H}_{12} \rightarrow \mathrm{C}_{5} \mathrm{H}_{5} \mathrm{~N}+{ }^{\cdot} \mathrm{C}_{6} \mathrm{H}_{11}+\mathrm{H}^{+} \\
\mathrm{C}_{5} \mathrm{H}_{5} \mathrm{~N}+{ }^{\cdot} \mathrm{C}_{6} \mathrm{H}_{11} \rightarrow\left[\mathrm{C}_{5} \mathrm{H}_{5} \mathrm{~N}-\mathrm{C}_{6} \mathrm{H}_{11}\right]^{\cdot} \\
{\left[\mathrm{C}_{5} \mathrm{H}_{5} \mathrm{~N}-\mathrm{C}_{6} \mathrm{H}_{11}\right]^{\cdot} \rightarrow \mathrm{C}_{11} \mathrm{H}_{10} \mathrm{~N}(\mathrm{CHPS})+\mathrm{H}^{\cdot}} \\
\mathrm{H}^{+}+\mathrm{H}^{\cdot}+\mathrm{e}^{-}{ }^{-} \mathrm{Pt}
\end{gathered}
$$

(A)

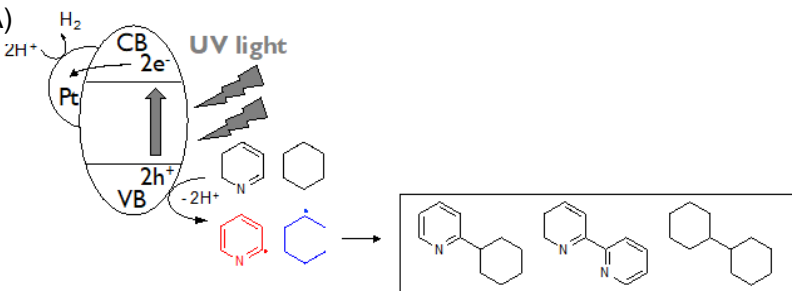

(B)

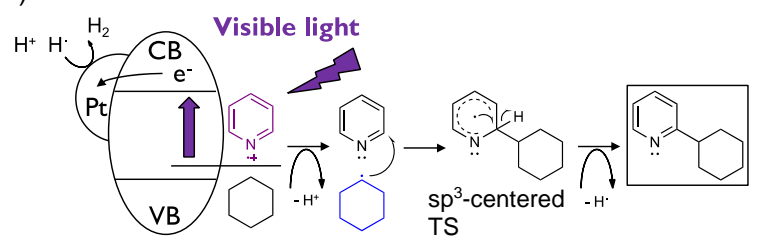

Fig. 4 Schematic image of tentative reaction mechanism under UV and visible light (A), and visible light (B). 2-CHP and 2,2'-BP were chosen as representative products among CHPs and BPs, respectively.

In each reaction tests, the yield was low. One of the reasons for that could be an insufficient number of the LMCT complex due to a limited number of the adsorption site. Thus, further study could be made to increase the LMCT sites by some methods such as surface treatment. Another reason could be an insufficient use of the LMCT band. In the current system, severe limitation of the irradiation wavelength was required to exclude the $\mathrm{TiO}_{2}$ photoexcitation due to the large overlap of the absorption bands of $\mathrm{LMCT}$ and $\mathrm{TiO}_{2}$, resulting in the limited use of the LMCT band, which leads to the low activity. Thus, to shift the LMCT band toward lower energy, surface modification of $\mathrm{TiO}_{2}$ or use of the molecules having higher HOMO level than that of pyridine might be helpful. If it is possible to use other photocatalyst having a positive valance band than $\mathrm{TiO}_{2}$, it is more preferred. 


\section{Conclusions}

Selective DCC reaction between pyridine and cyclohexane can be achieved by the unique reaction mechanism through the LMCT excitation of the acid-base interacted heteroaromatic surface complex consisting of pyridine and $\mathrm{TiO}_{2}$ under visible light irradiation. Although the yield of the reaction is not satisfying, this study showed the possibility of wide use of aromatic-semiconductor surface complex system for DCC, in which the selectivity can be improved just by changing the irradiation wavelength without any additives or modification of the photocatalyst.

\section{Conflicts of interest}

The authors declare no competing financial interests.

\section{Acknowledgements}

I would like to thank Prof. Ken-ichi Fujita, Mr. Mitsuki Onoda and Ms. Namino Morishima, Graduate School of Human and Environmental Studies, Kyoto University, for their help and guidance on the synthesis of the authentic sample of 2-CHP.

\section{Notes and references}

K. Hashimoto, H. Irie and A. Fujishima, Jpn. J. Appl. Phys. 2005, 44, 8269-8285. M. A. Fox and M. T. Dulay, Chem. Rev., 1993, 93, 341-357. O. Carp, C. L. Huisman and A. Reller, Prog. Solid State Chem., 2004, 32, 33-177. G. Palmisano, V. Augugliaro, M. Pagliaro and L. Palmisano, Chem. Commun., 2007, 0, 3425. H. Kisch, Angew. Chemie - Int. Ed., 2013, 52, 812-847.

L. E. Oi, M.-Y. Choo, H. V. Lee, H. C. Ong, S. B. A. Hamid and J. C. Juan, RSC Adv., 2016, 6, 108741-108754.

S. Higashimoto, N. Kitao, N. Yoshida, T. Sakura, M. Azuma, H. Ohue and Y. Sakata, J. Catal., 2009, 266, 279-285. G. Zhang, G. Kim and W. Choi, Energy Environ. Sci., 2014, 7 , 954-966. Sakata and H. Kobayashi, Curr. Org. Chem., 2013, 17, $2374-$ 2381. X. Lang, W. Ma, Y. Zhao, C. Chen, H. Ji and J. Zhao, Chem. A Eur. J., 2012, 18, 2624-2631.

11 X. Lang, W. Hao, W. R. Leow, S. Li, J. Zhao and X. Chen, Chem. Sci., 2015, 6, 5000-5005. C. Liu, D. Liu and A. Lei, Acc. Chem. Res., 2014, 47, 34593470. C. S. Yeung and V. M. Dong, Chem. Rev., 2011, 111, 12151292. M. Fagnoni, D. Dondi, D. Ravelli and A. Albini, Chem. Rev. 2007, 107, 2725-2756.

15 A. Yamamoto, T. Ohara and H. Yoshida, Catal. Sci. Technol., 2018, 8, 2046-2050.
A. R. Almeida, J. a Moulijn and G. Mul, J. Phys. Chem. C, 2011, 115, 1330-1338.

Y. R. Ruo, Handbook of Bond Dissociation Energies in Organic Compounds, CRC Press, 2002.

T. Bezrodna, G. Puchkovska, V. Shimanovska, I. Chashechnikova, T. Khalyavka and J. Baran, Appl. Surf. Sci., 2003, 214, 222-231.

T. Shishido, K. Teramura and T. Tanaka, Catal. Sci. Technol., 2011, 1, 541.

E. Heilbronner, V.Hornung, F. R.Pinkerton and S. F. Thames, Helv. Chim. Acta, 1972, 55, 289-302.

A. J. Bard, Science., 1980, 207, 139-144.

C. M. Wang, A. Heller and H. Gerischer, J. Am. Chem. Soc., 1992, 114, 5230-5234.

V. Subramanian, E. E. Wolf and P. V. Kamat, J. Am. Chem. Soc., 2004, 126, 4943-4950.

J. Yang, D. Wang, H. Han and C. Li, Acc. Chem. Res., 2013, 46, 1900-1909.

A. Tyagi, A. Yamamoto, T. Kato and H. Yoshida, Catal. Sci. Technol., 2017, 7, 2616-2623.

G. Zhang, C. Liu, H. Yi, Q. Meng, C. Bian, H. Chen, J. X. Jian, L. Z. Wu and A. Lei, J. Am. Chem. Soc., 2015, 137, 92739280. 